\title{
Regulation of RAGE for Attenuating Progression of Diabetic Vascular Complications
}

\author{
Myat Thu Thu Win, Yasuhiko Yamamoto, Seiichi Munesue, Hidehito Saito, Dong Han, \\ So Motoyoshi, Tarek Kamal, Takuro Ohara, Takuo Watanabe, and Hiroshi Yamamoto
} Department of Biochemistry and Molecular Vascular Biology, Kanazawa University Graduate School of Medical Science,
Kanazawa 920-8640, Japan

Correspondence should be addressed to Yasuhiko Yamamoto, yasuyama@med.kanazawa-u.ac.jp

Received 23 July 2011; Revised 8 August 2011; Accepted 16 August 2011

Academic Editor: Daisuke Koya

Copyright ( $) 2012$ Myat Thu Thu Win et al. This is an open access article distributed under the Creative Commons Attribution License, which permits unrestricted use, distribution, and reproduction in any medium, provided the original work is properly cited.

Diabetic angiopathy including micro- and macroangiopathy is concerned with high rate of morbidity and mortality in patients with long-standing diabetes. Receptor for advanced glycation end products (RAGE) and its ligands have been considered as important pathogenic triggers for the progression of the vascular injuries in diabetes. The deleterious link between RAGE and diabetic angiopathy has been demonstrated in animal studies. Preventive and therapeutic strategies focusing on RAGE and its ligand axis may be of great importance in relieving diabetic vascular complications and reducing the burden of disease.

\section{Introduction}

Diabetes is a life-threatening disease attributing to its devastating complications such as cardiovascular disease, stroke, and microvascular diseases. The population worldwide with diabetes is estimated to be 285 million adults in 2010, and it will reach 439 million adults by 2030 with overall total predicted $54 \%$ increase [1]. The very recent study reports the number of people with diabetes already came to 347 million in 2008 [2]. In proportion to the rapid increase of diabetic population, diabetic nephropathy is now a major cause of end-stage renal disease and diabetic retinopathy is a leading cause of blindness [3]. Extensive intracellular and extracellular formation of advanced glycation endproducts (AGE) is considered to be a causative factor in sustained hyperglycemia-induced vascular injuries in diabetes. Receptor-dependent and receptor independent mechanisms are known to work in the AGE-induced cellular dysfunction and tissue damage. The receptor for AGE (RAGE) is originally found as an AGE-binding receptor and now recognized as a proinflammatory molecular devise mediating danger signals to the body. In this paper, our current understanding about RAGE and its multiligand system will be reviewed remarkably in the development and progression of diabetic vascular complications and in possible therapeutic targets for these diseases.

\section{AGE}

Maillard first described the formation of brown-colored substances resulted from nonenzymatic reaction between reducing sugar and proteins [4]. There is a chemical linkage between the carbonyl groups and the amino group to form Schiff bases and then Amadori compounds, followed by irreversible dehydration, condensation, and crosslinking, resulting in heterogeneous derivatives termed AGE [5]. Similar reactions have been found to occur with nonglucose materials containing an aldehyde group by enzymatic and non-enzymatic pathways. Metabolites from glycolysis pathway such as dicarbonyls of methylglyoxal (MG), glyoxal, and 3-deoxyglucosone (3DG) are known to interact with protein residues to rapidly form AGE [6]. Reactive dicarbonyls can be also generated from ketones, lipids, and other metabolic pathways [7]. Increased production of the reactive dicarbonyls or reducing detoxification by the glyoxalase system or endogenous scavengers leads to a state of carbonyl stress, which is increasingly considered to be the major driving force for AGE formation and accumulation [8]. 


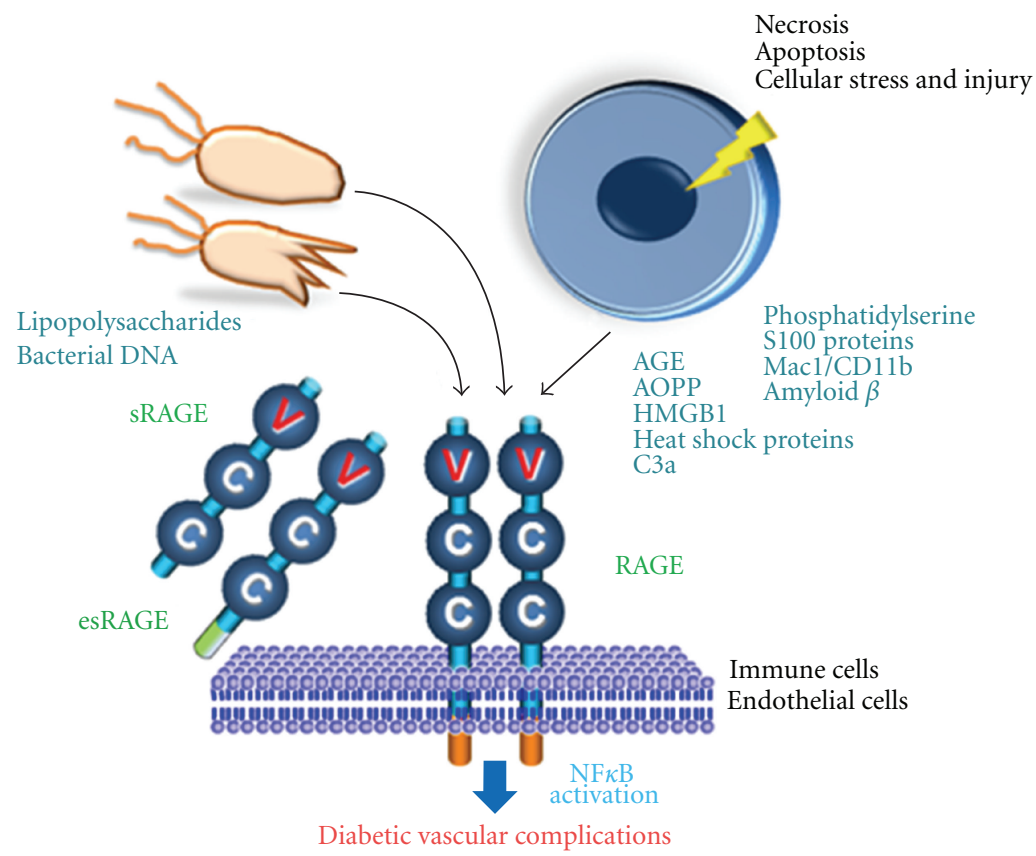

FIGURE 1: RAGE and its ligands play a role in the development of diabetic vascular complications. Soluble RAGE (sRAGE) and endogenous soluble RAGE (esRAGE) may work as decoy receptors against ligand-RAGE interactions. AGE: advanced glycation end product; AOPP: advanced oxidation protein product; HMGB1: high-mobility group box protein 1 .

Glyoxal is also produced by auto-oxidation of glucose and 3-deoxyglucosone (3DG) generated by hydrolysis from Amadori rearrangement products [9]. Glycolaldehyde production by myeloperoxidase from activated macrophages and neutrophils plays a pathogenic role in generating AGE and damaging tissues at sites of inflammation [10]. Formation of AGE is accelerated under hyperglycemia in diabetes. Some AGE have intrinsic fluorescence which can be used as a surrogate marker for the presence of AGE modifications. AGE are chemically heterogeneous groups of compounds with only 25 AGE structures fully characterized. $\mathrm{N}^{\varepsilon}$-carboxymethyl-lysine (CML) is the simplest and best characterized AGE and the main epitope for recognition by most commercially available antibodies used for the detection and quantification of AGE. Exogenously offered AGE are absorbed in the gastrointestinal tract $(\sim 10 \%)$, and approximately two-thirds remained in contact with tissues for $>72 \mathrm{hr}$, whereas the rest is rapidly excreted by the kidneys [11-13]. Reducing basal oxidative stress by AGE restriction in mice, without energy or nutrient change, alleviates inflammation, prevents vascular complications, and extends normal life span $[14,15]$.

\section{RAGE}

The best characterized AGE receptor is RAGE. RAGE belongs to the immunoglobulin (Ig) superfamily of cellsurface molecules and is composed of an extracellular region containing one V-type and two C-type Ig domains [16]. This portion of the receptor joins a hydrophobic transmembranespanning domain and then a highly charged, short cytoplasmic domain that is essential for post-RAGE signaling
$[16,17]$. RAGE is a member of a family of patternrecognition receptors that function at the interface of innate and adaptive immunity. Its endogenous and exogenous binding partners include AGE, high-mobility group box 1 (HMGB1), calcium-binding S100 protein group, $\beta 2$-integrin Mac/CD11b, amyloid $\beta$-peptide, $\beta$-sheet fibrils, advanced oxidation protein products (AOPPs), complement C3a, lipopolysaccharides (LPS), and phosphatidylserine on the surface of apoptotic cells [18-24] (Figure 1). Ligand engagement of RAGE activates the nuclear factor $-\kappa \mathrm{B}(\mathrm{NF}-\kappa \mathrm{B})$ and other signaling pathways through stimulation of ERK (extracellular signal-regulated kinase)1/2, p38 MAPK (mitogenactivated-protein-kinase)-JNK (c-Jun N-terminal kinases), JAK (Janus-kinase)-STAT (signal transducer and activator of transcription), and Rac-Cdc42, many of which are the results as well as the cause of reactive oxygen species (ROS) [25]. Subsequently, expression of inflammatory cytokines is increased, which leads to an inflammatory response with associated cellular migration and proliferation. Recently, mammalian homologue of Drosophila gene Diaphanous 1 (mDial) has been identified as a direct binding partner of an intracellular domain of RAGE and as a part of the machinery of RAGE intracellular signaling [26]. The mDial exists widely from yeast to the mammal and is known to link with cell division, polarity formation, and movements by actin polymerization [26]. Ligation of RAGE causes a positive feed-forward loop, in which inflammatory stimuli activate NF- $\kappa \mathrm{B}$, which induces RAGE expression, followed again by NF- $\kappa \mathrm{B}$ activation [27].

Self-downregulation system of RAGE is also reported: as an example, the binding of HMGB1 to RAGE induces an intracellular signal transduction as well as RAGE shedding 
by a disintegrin and metalloproteinase domain-containing protein 10 (ADAM10) [28]. The cleavage of the membranebound full-length and signal transducing RAGE yields soluble RAGE (sRAGE), which could work as a decoy receptor against ligand-RAGE interactions. In the strict sense of the word, sRAGE is a heterogeneous population of total sRAGE proteins, including soluble splice variants of RAGE and the proteinase-cleaved forms of membrane-bound RAGE and of the soluble splice variants [29]. Endogenous secretory RAGE (esRAGE) is one of the major splice variants of RAGE detected in blood, cell surface and cytoplasm of vascular endothelial cells, pancreatic $\beta$-cells, monocytes, macrophages, and so on $[30,31]$. The sRAGE is thought to act locally and systemically as a decoy receptor. Reinforcing the ectodomain shedding will decrease a total amount and expression of signal-transducing RAGE and will reciprocally increase an amount of decoy receptor sRAGE; this can control ligand-RAGE signaling and subsequent cellular and tissue derangement [32]. It is also reported that sRAGE mediates inflammation by directly binding to monocytes under less ligand conditions though the mechanism of action is unknown [33]. Recent clinical studies have focused on the significance of circulating sRAGE or esRAGE in diabetic vascular complications. Findings in both type 1 and type 2 diabetic patients are quite confusing and both inverse and positive correlations have been reported in diabetic retinopathy, nephropathy, and incident cardiovascular disease events and mortality outcomes [29, 34-39]. First, production of sRAGE and esRAGE is inducible. Second, the presence of renal insufficiency can strongly and positively influence circulating sRAGE or esRAGE level [29]. Third, medications may alter sRAGE or esRAGE level. All phenomena may explain controversial findings of sRAGE or esRAGE in diabetes.

\section{Other Receptors}

Many other AGE receptors and soluble binding proteins interacting with AGE may play an important role in the AGE homeostasis: scavenger receptors class A (MSR-A), class B (MSR-B) (CD36 and LOX1), AGE-R1 (OST48 oligosaccharyltransferase), AGE-R2 (80K-H protein kinase C substrate), AGE-R3 (galectin-3), and toll-like receptor (TLR) 4 [40-44]. There are also other molecules like lysozyme and lactoferrinlike polypeptide involving in cellular uptake and degradation of AGE [45]. AGE-R1 is a type I transmembrane receptor found on the plasma membrane and in the endoplasmic reticulum [40]. The cell surface membrane-associated AGE$\mathrm{R} 1$ blocks responses to AGE by blocking the induction of ROS-mediated activation of MAPK/Ras and inflammatory molecules, induced in part via RAGE [46]. Torreggiani et al. showed that the overexpression of AGE-R1 in mice is associated with decreased basal levels of circulating and tissue AGE and oxidative stress and significant protection against wire injury-induced femoral artery intimal hyperplasia and inflammation [47]. AGE-R3 (galectin-3) is also reported to work as an AGE receptor to protect AGE-induced tissue injury via AGE removal or degradation $[41,42]$.

\section{Diabetic Nephropathy}

To evaluate whether RAGE and ligand system may participate in the development of diabetic nephropathy, we created transgenic mice that overexpress human RAGE proteins in endothelial cells and crossbred them with another transgenic mouse line that develops insulin-dependent diabetes early after birth [48]. The resultant double transgenic mice showed significant increases in kidney weight, albuminuria, glomerulosclerosis, and serum creatinine compared with the diabetic control [48-50]. Indices diagnostic of diabetic retinopathy were also most prominent in double transgenic mice. Our group also generated RAGE knockout (KO) mice and reported the marked improvement of nephromegaly, albuminuria, glomerulosclerosis, and increase of serum creatinine level in diabetic RAGE-KO mice [51]. The kidneys of streptozotocin (STZ)-injected RAGE-KO mice were reported to be protected from early mesangial matrix expansion and thickening of the glomerular basement membrane (GBM) seen in wild-type diabetic mice [52]. Moreover, RAGE deletion was also beneficial to diabetic nephropathy seen in OVE26 type 1 diabetic mice with progressive glomerulosclerosis and decline of renal function [53]. Rüster et al. reported an interaction between the renin-angiotensin system and the AGE-RAGE axis in podocytes [54]. Since intraglomerular angiotensin II levels are increased in diabetic nephropathy, this interaction may have pathophysiological consequences for podocyte injury and inflammation associated with the development of diabetic nephropathy [54]. Pharmacological blockade of RAGE, using sRAGE in $d b / d b$ diabetic mice, protected against glomerulosclerosis and other classical lesions of early diabetic nephropathy [52]. It admits no doubt that RAGE plays a major role in diabetic nephropathy (Table 1).

\section{Diabetic Retinopathy}

Diabetes retinopathy is classified into nonproliferative stage (NPDR) and proliferative stage (PDR). NPDR is characterized by capillary microangiopathy, microaneurysms, basement membrane thickening, and loss of pericytes [55]. An association between accumulation of CML and expression of vascular endothelial growth factor (VEGF) has also been found in eyes with non-PDR and PDR [56]. VEGF appears to be the most important growth factor in diabetic retinopathy. It is also well documented that oxidative stress is linked to AGE formation, and involved in retinal vascular dysfunction [57]. RAGE expression has been predominantly localized to glia in the inner retina, and the expression appeared to be upregulated in diabetic conditions [58]. Other ligands for RAGE including S100 proteins and HMGB1 are evident in the vitreous and preretinal membranes of eyes with PDR [59]. Kaji et al. demonstrated blood-retinal barrier breakdown and increased leukostasis in endothelial RAGEoverexpressing mice and their amelioration by the treatment of sRAGE [60]. RAGE activation by ligand in Müller glia results in ERK1/2 activation and subsequent production 
TABLE 1: RAGE and its ligand axis in diabetic angiopathy using RAGE gene-manipulated animal models.

\begin{tabular}{|c|c|c|}
\hline Animal models & Phenotypes & References \\
\hline \multicolumn{3}{|l|}{ Diabetic nephropathy } \\
\hline RAGE transgenic mice & Nephropathy $\uparrow$ & {$[48,50]$} \\
\hline \multicolumn{3}{|l|}{ (Type 1 diabetes) } \\
\hline + AGE inhibitor & Nephropathy $\downarrow$ & \\
\hline RAGE knockout mice & Nephropathy $\downarrow$ & {$[51,93]$} \\
\hline \multicolumn{3}{|l|}{ (Type 1 diabetes) } \\
\hline + LMWH treatment & Nephropathy $\downarrow$ & \\
\hline RAGE knockout mice & Nephropathy $\downarrow$ & {$[53]$} \\
\hline \multicolumn{3}{|l|}{ (Type 1 diabetes, OVE26) } \\
\hline$d b / d b$ mice + sRAGE & Nephropathy $\downarrow$ & {$[52]$} \\
\hline RAGE knockout mice & Nephropathy $\downarrow$ & \\
\hline \multicolumn{3}{|l|}{ (STZ-diabetes) } \\
\hline \multicolumn{3}{|l|}{ Diabetic retinopathy } \\
\hline RAGE transgenic mice & Retinopathy $\uparrow$ & {$[60]$} \\
\hline \multicolumn{3}{|l|}{ (STZ-diabetes) } \\
\hline+ sRAGE treatment & Retinopathy $\downarrow$ & \\
\hline RAGE transgenic mice & Retinopathy $\uparrow$ & {$[80]$} \\
\hline \multicolumn{3}{|l|}{ (Type 1 diabetes) } \\
\hline \multicolumn{3}{|l|}{ Diabetic neuropathy } \\
\hline RAGE knockout mice & Neuropathy $\downarrow$ & {$[63]$} \\
\hline \multicolumn{3}{|l|}{ (STZ diabetes) } \\
\hline+ sRAGE treatment & Neuropathy $\downarrow$ & \\
\hline RAGE knockout mice & Neuropathy $\downarrow$ & {$[64]$} \\
\hline (STZ diabetes) & & \\
\hline
\end{tabular}

of inflammatory cytokines such as VEGF and MCP-1, implicating the critical role of RAGE in neovascularization and recruitment of immune cells such as microglia into the deep retinal layers during diabetic retinopathy to induce inflammation [58].

\section{Diabetic Neuropathy}

In diabetic neuropathy, both autonomic and peripheral nerves are affected. Endothelial injury may impair the blood flow which leads to hypoxia and oxidative stress in peripheral nerves [61]. Wada and Yagihashi demonstrated the expression of RAGE in the perineural and endoneurial endothelial cells and schwann cells of peripheral nerve in rat by in situ hybridization [62]. Models of experimental diabetic neuropathy provided sound evidence that deletion of the RAGE gene protected animals from the detrimental effects of diabetes, while overexpression of RAGE promotes diabetic neuropathy [63-66]. Moreover, the loss of thermal pain perception observed in mice with diabetes could be prevented by treatment with sRAGE. In agreement with these observations, NF- $\kappa \mathrm{B}$ activation and the loss of pain perception were largely blunted in RAGE-KO mice [63].

\section{Atherosclerosis}

AGE stimulate ROS generation in vascular wall cells and subsequently induce redox-sensitive atherosclerosisrelated molecular expressionsuch as MCP-1, matrix metalloproteinase-9 (MMP-9), and plasminogen activator inhibitor1 (PAI-1), all of which could contribute to the formation and destabilization of coronary atherosclerotic plaques [67, 68]. AGE induce increased vascular permeability, procoagulant activity, migration of macrophages and $\mathrm{T}$ cells into the intima, and impairment of endothelium-dependent relaxation [69]. AGE inhibition attenuated accelerated atheroma associated with diabetes [70]. STZ-induced diabetic ApoEKO mice clearly showed that RAGE activation has a central role in the formation and progression of atherosclerotic lesions and that the absence of RAGE was associated with a significant attenuation of the atherosclerotic plaque [71]. Competitive inhibition of RAGE by exogenously administrated sRAGE resulted in a decrease in mean atherosclerotic lesion area and number of complex lesions [72, 73]. In addition, RAGE inactivation also inhibited atherosclerosis through blocking the RAGE-mediated inflammatory reactions and oxidative stress in nondiabetic models with atherosclerosis of ApoE-KO and low-density lipoprotein (LDL) receptor $\mathrm{KO}$ mice [74].

In atherosclerosis, increased level of LDL and presence of small dense LDL are strong and independent risk factors and both are features of dyslipidemia [75]. The specific protein of apolipoprotein B (ApoB) on LDL is glycated in diabetes [76], and this leads to rapid scavenger uptake of the LDL [77], which gives rise to foam cell formation in atherogenesis [69]. The oxidation and glycation of LDL are partially interdependent and indisputably coexist, and both prevent LDL receptor-mediated uptake and promote macrophage scavenger receptor-mediated LDL uptake. Small dense LDL is more preferentially glycated in vivo and more susceptible to glycation in vitro than buoyant LDL [78]. Glycated-high density lipoprotein (HDL) has also been linked to decreased ability to prevent monocyte adhesion to aortic endothelial cells [79], while lipoprotein A glycation has been shown to increase PAI-1 production and decrease t-PA generation $[80,81]$. Glycated LDL and HDL may also play an important role in atherogenesis.

\section{Conclusion}

Diabetic angiopathy is still a burden disease worldwide even though new pharmaceutical interventions are available. Applications of inhibitors for AGE and RAGE may be prospective therapeutic approaches for prophylaxis and treatment of diabetic angiopathy. Benfotiamine is a synthetic $\mathrm{S}$-acyl derivative of thiamine and has antioxidant and antiAGE formation properties [82]. Thiazolium compounds ALT-711 (algebrium), C36, TRC4186, and TRC4149 and their prototype $N$-phenacylthiazolium bromide (PTB) are known as AGE breakers, which break preaccumulated AGE or existing AGE cross-links [83-86].

TTP488 is an antagonist against RAGE [87]. Lowmolecular-weight heparin (LMWH) can bind RAGE and act 
as an antagonist to RAGE [51]. LMWH treatment of mice showed preventive and therapeutic effects on albuminuria and increased glomerular cell number, mesangial expansion, and advanced glomerulosclerosis in a dose-dependent manner [51]. Thiazolidinediones, calcium channel blockers, angiotensin-converting enzyme inhibitors (ACEIs), angiotensin II receptor blockers (ARBs), and statins are reported to suppress RAGE expression [88-90]. Treatment of statins and ACEI stimulated circulating sRAGE production in human studies [91, 92]. It is interesting in the future to develop new devices and remedies of controlling the RAGE ectodomain shedding. New therapeutic strategies are desired to prevent diabetic vascular complications and to improve both quantity and quality of life in patients with diabetes.

\section{References}

[1] J. E. Shaw, R. A. Sicree, and P. Z. Zimmet, "Global estimates of the prevalence of diabetes for 2010 and 2030," Diabetes Research and Clinical Practice, vol. 87, no. 1, pp. 4-14, 2010.

[2] G. Danaei, M. M. Finucane, Y. Lu et al., "National, regional, and global trends in fasting plasma glucose and diabetes prevalence since 1980: systematic analysis of health examination surveys and epidemiological studies with 370 country-years and 2.7 million participants," The Lancet, vol. 2, no. 378, pp. 31-40, 2011.

[3] Diabetes statistics, Data from the 2011 national diabetes fact sheet, 2011, http://www.diabetes.org/diabetes-basics/diabetesstatistics.

[4] L. C. Maillard, "Action des acides aminés sur les sucres: formation des mélanoïdines par voie méthodique," Compterendu de l'Académie des sciences, pp. 66-68, 1912.

[5] H. Yamamoto, T. Watanabe, Y. Yamamoto et al., "RAGE in diabetic nephropathy," Current Molecular Medicine, vol. 7, no. 8, pp. 752-757, 2007.

[6] N. Rabbani and P. J. Thornalley, "Dicarbonyls linked to damage in the powerhouse: glycation of mitochondrial proteins and oxidative stress," Biochemical Society Transactions, vol. 36, no. 5, pp. 1045-1050, 2008.

[7] V. Riddle and F. W. Lorenz, "Nonenzymic, polyvalent anioncatalyzed formation of methylglyoxal as an explanation of its presence in physiological systems," Journal of Biological Chemistry, vol. 243, no. 10, pp. 2718-2724, 1968.

[8] P. J. Thornalley, "The glyoxalase system: new developments towards functional characterization of a metabolic pathway fundamental to biological life," Biochemical Journal, vol. 269, no. 1, pp. 1-11, 1990.

[9] R. Nagai, C. M. Hayashi, L. Xia, M. Takeya, and S. Horiuchi, "Identification in human atherosclerotic lesions of GApyridine, a novel structure derived from glycolaldehydemodified proteins," Journal of Biological Chemistry, vol. 277, no. 50, pp. 48905-48912, 2002.

[10] R. Nagai, K. Matsumoto, X. Ling, H. Suzuki, T. Araki, and S. Horiuchi, "Glycolaldehyde, a reactive intermediate for advanced glycation end products, plays an important role in the generation of an active ligand for the macrophage scavenger receptor," Diabetes, vol. 49, no. 10, pp. 1714-1723, 2000.

[11] T. Koschinsky, C. J. He, T. Mitsuhashi et al., "Orally absorbed reactive glycation products (glycotoxins): an environmental risk factor in diabetic nephropathy," Proceedings of the National Academy of Sciences of the United States of America, vol. 94, no. 12, pp. 6474-6479, 1997.
[12] H. Vlassara, W. Cai, J. Crandall et al., "Inflammatory markers are induced by dietary glycotoxins: a pathway for accelerated atherosclerosis in diabetes," Proceedings of the National Academy of Sciences of the United States of America, vol. 99, no. 24, pp. 15596-15601, 2002.

[13] W. Cai, Q. D. Gao, L. Zhu, M. Peppa, C. He, and H. Vlassara, "Oxidative stress-inducing carbonyl compounds from common foods: novel mediators of cellular dysfunction," Molecular Medicine, vol. 8, no. 7, pp. 337-346, 2002.

[14] M. Peppa, C. He, M. Hattori, R. McEvoy, F. Zheng, and H. Vlassara, "Fetal or neonatal low-glycotoxin environment prevents autoimmune diabetes in NOD mice," Diabetes, vol. 52, no. 6, pp. 1441-1448, 2003.

[15] H. Vlassara and G. E. Striker, "AGE restriction in diabetes mellitus: a paradigm shift," Nature Reviews Endocrinology, vol. 7, no. 9, pp. 526-539, 2011.

[16] M. Neeper, A. M. Schmidt, J. Brett et al., "Cloning and expression of a cell surface receptor for advanced glycosylation end products of proteins," Journal of Biological Chemistry, vol. 267, no. 21, pp. 14998-15004, 1992.

[17] H. J. Huttunen, C. Fages, and H. Rauvala, "Receptor for advanced glycation end products (RAGE)-mediated neurite outgrowth and activation of NF- $\kappa \mathrm{B}$ require the cytoplasmic domain of the receptor but different downstream signaling pathways," Journal of Biological Chemistry, vol. 274, no. 28, pp. 19919-19924, 1999.

[18] T. Kislinger, C. Fu, B. Huber et al., "N( $(\varepsilon)$-(carboxymethyl)lysine adducts of proteins are ligands for receptor for advanced glycation end products that activate cell signaling pathways and modulate gene expression," Journal of Biological Chemistry, vol. 274, no. 44, pp. 31740-31749, 1999.

[19] M. A. Hofmann, S. Drury, C. Fu et al., "RAGE mediates a novel proinflammatory axis: a central cell surface receptor for S100/calgranulin polypeptides," Cell, vol. 97, no. 7, pp. 889-901, 1999.

[20] O. Hori, J. Brett, T. Slattery et al., "The receptor for advanced glycation end products (RAGE) is a cellular binding site for amphoterin. Mediation of neurite outgrowth and coexpression of RAGE and amphoterin in the developing nervous system," Journal of Biological Chemistry, vol. 270, no. 43, pp. 25752-25761, 1995.

[21] S. D. Yan, X. Chen, J. Fu et al., "RAGE and amyloid- $\beta$ peptide neurotoxicity in Alzheimer's disease," Nature, vol. 382, no. 6593, pp. 685-691, 1996.

[22] T. Chavakis, A. Bierhaus, N. Al-Fakhri et al., "The pattern recognition receptor (RAGE) is a counterreceptor for leukocyte integrins: a novel pathway for inflammatory cell recruitment," Journal of Experimental Medicine, vol. 198, no. 10, pp. 1507-1515, 2003.

[23] Y. Yamamoto, A. Harashima, H. Saito et al., "Septic shock is associated with receptor for advanced glycation end products ligation of LPS," Journal of Immunology, vol. 186, no. 5, pp. 3248-3257, 2011.

[24] M. He, H. Kubo, K. Morimoto et al., "Receptor for advanced glycation end products binds to phosphatidylserine and assists in the clearance of apoptotic cells," EMBO Reports, vol. 12, no. 4, pp. 358-364, 2011.

[25] D. P. Barlovic, A. Soro-Paavonen, and K. A. M. JandeleitDahm, "RAGE biology, atherosclerosis and diabetes," Clinical Science, vol. 121, no. 2, pp. 43-55, 2011.

[26] B. I. Hudson, A. Z. Kalea, M. D. M. Arriero et al., "Interaction of the RAGE cytoplasmic domain with diaphanous-1 is required for ligand-stimulated cellular migration through 
activation of Rac1 and Cdc42," Journal of Biological Chemistry, vol. 283, no. 49, pp. 34457-34468, 2008.

[27] A. Bierhaus, S. Schiekofer, M. Schwaninger et al., "Diabetesassociated sustained activation of the transcription factor nuclear factor- $\kappa$ B," Diabetes, vol. 50, no. 12, pp. 2792-2808, 2001.

[28] A. Raucci, S. Cugusi, A. Antonelli et al., "A soluble form of the receptor for advanced glycation endproducts (RAGE) is produced by proteolytic cleavage of the membrane-bound form by the sheddase a disintegrin and metalloprotease 10 (ADAM10)," FASEB Journal, vol. 22, no. 10, pp. 3716-3727, 2008.

[29] Y. Yamamoto, J. Miura, S. Sakurai et al., "Assaying soluble forms of receptor for advanced glycation end products," Arteriosclerosis, Thrombosis, and Vascular Biology, vol. 27, no. 6, pp. e33-e34, 2007.

[30] H. Yonekura, Y. Yamamoto, S. Sakurai et al., "Expression and function of novel splice variants of RAGE in human vascular endothelial cells and pericytes," Biochemical Journal, vol. 370, no. 3, pp. 1097-1109, 2003.

[31] C. Cheng, K. Tsuneyama, R. Kominami et al., "Expression profiling of endogenous secretory receptor for advanced glycation end products in human organs," Modern Pathology, vol. 18, no. 10, pp. 1385-1396, 2005.

[32] R. Nagai, T. Mori, Y. Yamamoto, Y. Kaji, and Y. Yonei, "Significance of advanced glycation end products (AGEs) in aging-related disease," Anti-Aging Medicine, vol. 7, no. 10, pp. 112-119, 2010.

[33] Y. Wang, H. Wang, M. G. Piper et al., "sRAGE induces human monocyte survival and differentiation," Journal of Immunology, vol. 185, no. 3, pp. 1822-1835, 2010.

[34] S. Sakurai, Y. Yamamoto, H. Tamei et al., "Development of an ELISA for esRAGE and its application to type 1 diabetic patients," Diabetes Research and Clinical Practice, vol. 73, no. 2, pp. 158-165, 2006.

[35] H. Koyama, T. Shoji, S. Fukumoto et al., "Low circulating endogenous secretory receptor for AGEs predicts cardiovascular mortality in patients with end-stage renal disease," Arteriosclerosis, Thrombosis, and Vascular Biology, vol. 27, no. 1, pp. 147-153, 2007.

[36] N. Katakami, M. Matsuhisa, H. Kaneto et al., "Serum endogenous secretory RAGE level is an independent risk factor for the progression of carotid atherosclerosis in type 1 diabetes," Atherosclerosis, vol. 204, no. 1, pp. 288-292, 2009.

[37] X. H. Tam, S. W. Shiu, L. Leng, R. Bucala, D. J. Betteridge, and K. C. Tan, "Enhanced expression of receptor for advanced glycation end-products is associated with low circulating soluble isoforms of the receptor in type 2 diabetes," Clinical Science, vol. 120, no. 2, pp. 81-89, 2011.

[38] M. C. Thomas, J. Söderlund, M. Lehto et al., "Soluble receptor for AGE (RAGE) is a novel independent predictor of all-cause and cardiovascular mortality in type 1 diabetes," Diabetologia, vol. 54, no. 10, pp. 2669-2677, 2011.

[39] H. M. Colhoun, D. J. Betteridge, and P. Durrington, "Total soluble and endogenous secretory receptor for advanced glycation endproducts as predictive biomarkers of coronary heart disease risk in patients with type 2 diabetes: an analysis from the CARDS Trial," Diabetes, vol. 60, no. 9, pp. 2379-2385, 2011.

[40] Z. Yang, Z. Makita, Y. Horii et al., "Two novel rat liver membrane proteins that bind advanced glycosylation endproducts: relationship to macrophage receptor for glucose-modified proteins," Journal of Experimental Medicine, vol. 174, no. 3, pp. 515-524, 1991.

[41] H. Vlassara, Y. M. Li, Y. Imani et al., "Identification of galectin3 as a high-affinity binding protein for advanced glycation end products (AGE): a new member of the AGE-receptor complex," Molecular Medicine, vol. 1, no. 6, pp. 634-646, 1995.

[42] W. Zhu, H. Sano, R. Nagai, K. Fukuhara, A. Miyazaki, and S. Horiuchi, "The role of galectin-3 in endocytosis of advanced glycation end products and modified low density lipoproteins," Biochemical and Biophysical Research Communications, vol. 280, no. 4, pp. 1183-1188, 2001.

[43] H. Suzuki, Y. Kurihara, M. Takeya et al., "A role for macrophage scavenger receptors in atherosclerosis and susceptibility to infection," Nature, vol. 386, no. 6633, pp. 292-296, 1997.

[44] C. P. Hodgkinson, R. C. Laxton, K. Patel, and S. Ye, "Advanced glycation end-product of low density lipoprotein activates the toll-like 4 receptor pathway implications for diabetic atherosclerosis," Arteriosclerosis, Thrombosis, and Vascular Biology, vol. 28, no. 12, pp. 2275-2281, 2008.

[45] T. Mitsuhashi, Y. M. Li, S. Fishbane, and H. Vlassara, "Depletion of reactive advanced glycation end products from diabetic uremic sera using a lysozyme-linked matrix," Journal of Clinical Investigation, vol. 100, no. 4, pp. 847-854, 1997.

[46] C. Lu, J. C. He, W. Cai, H. I. Liu, L. Zhu, and H. Vlassara, "Advanced glycation endproduct (AGE) receptor 1 is a negative regulator of the inflammatory response to AGE in mesangial cells," Proceedings of the National Academy of Sciences of the United States of America, vol. 101, no. 32, pp. 11767-11772, 2004.

[47] M. Torreggiani, H. Liu, J. Wu et al., "Advanced glycation end product receptor-1 transgenic mice are resistant to inflammation, oxidative stress, and post-injury intimal hyperplasia," American Journal of Pathology, vol. 175, no. 4, pp. 1722-1732, 2009.

[48] Y. Yamamoto, I. Kato, T. Doi et al., "Development and prevention of advanced diabetic nephropathy in RAGEoverexpressing mice," Journal of Clinical Investigation, vol. 108, no. 2, pp. 261-268, 2001.

[49] Y. Yamamoto, S. Yamagishi, H. Yonekura et al., "Roles of the AGE-RAGE system in vascular injury in diabetes," Annals of the New York Academy of Sciences, vol. 902, pp. 163-172, 2000.

[50] R. Inagi, Y. Yamamoto, M. Nangaku et al., "A severe diabetic nephropathy model with early development of nodule-like lesions induced by megsin overexpression in RAGE/iNOS transgenic mice," Diabetes, vol. 55, no. 2, pp. 356-366, 2006.

[51] K. M. Myint, Y. Yamamoto, T. Doi et al., "RAGE control of diabetic nephropathy in a mouse model: effects of RAGE gene disruption and administration of low-molecular weight heparin," Diabetes, vol. 55, no. 9, pp. 2510-2522, 2006.

[52] T. M. Wendt, N. Tanji, J. Guo et al., "RAGE drives the development of glomerulosclerosis and implicates podocyte activation in the pathogenesis of diabetic nephropathy," American Journal of Pathology, vol. 162, no. 4, pp. 1123-1137, 2003.

[53] N. Reiniger, K. Lau, D. McCalla et al., "Deletion of the receptor for advanced glycation end products reduces glomerulosclerosis and preserves renal function in the diabetic OVE26 mouse," Diabetes, vol. 59, no. 8, pp. 2043-2054, 2010.

[54] C. Rüster, T. Bondeva, S. Franke, N. Tanaka, H. Yamamoto, and G. Wolf, "Angiotensin II upregulates RAGE expression on podocytes: role of AT2 receptors," American Journal of Nephrology, vol. 29, no. 6, pp. 538-550, 2009. 
[55] H. P. Hammes, "Pericytes and the pathogenesis of diabetic retinopathy," Hormone and Metabolic Research, vol. 37, no. 1, pp. S39-S43, 2005.

[56] T. Murata, R. Nagai, T. Ishibashi, H. Inomata, K. Ikeda, and S. Horiuchi, "The relationship between accumulation of advanced glycation end products and expression of vascular endothelial growth factor in human diabetic retinas," Diabetologia, vol. 40, no. 7, pp. 764-769, 1997.

[57] T. Soulis, V. Thallas, S. Youssef et al., "Advanced glycation end products and their receptors co-localise in rat organs susceptible to diabetic microvascular injury," Diabetologia, vol. 40, no. 6, pp. 619-628, 1997.

[58] H. Zong, M. Ward, A. Madden et al., "Hyperglycaemiainduced pro-inflammatory responses by retinal Müller glia are regulated by the receptor for advanced glycation end-products (RAGE)," Diabetologia, vol. 53, no. 12, pp. 2656-2666, 2010.

[59] S. I. Pachydaki, S. R. Tari, S. E. Lee et al., "Upregulation of RAGE and its ligands in proliferative retinal disease," Experimental Eye Research, vol. 82, no. 5, pp. 807-815, 2006.

[60] Y. Kaji, T. Usui, S. Ishida et al., "Inhibition of diabetic leukostasis and blood-retinal barrier breakdown with a soluble form of a receptor for advanced glycation end products," Investigative Ophthalmology and Visual Science, vol. 48, no. 2, pp. 858-865, 2007.

[61] N. E. Cameron, S. E. Eaton, M. A. Cotter, and S. Tesfaye, "Vascular factors and metabolic interactions in the pathogenesis of diabetic neuropathy," Diabetologia, vol. 44, no. 11, pp. 1973-1988, 2001.

[62] R. Wada and S. Yagihashi, "Role of advanced glycation end products and their receptors in development of diabetic neuropathy," Annals of the New York Academy of Sciences, vol. 1043, pp. 599-603, 2005.

[63] A. Bierhaus, K. M. Haslbeck, P. M. Humpert et al., "Loss of pain perception in diabetes is dependent on a receptor of the immunoglobulin superfamily," Journal of Clinical Investigation, vol. 114, no. 12, pp. 1741-1751, 2004.

[64] C. Toth, L. L. Rong, C. Yang et al., "Receptor for advanced glycation end products (RAGE) and experimental diabetic neuropathy," Diabetes, vol. 57, no. 4, pp. 1002-1017, 2008.

[65] N. Yajima, Y. Yamamoto, H. Yamamoto et al., "Peripheral neuropathy in diabetic mice overexpressing receptor for advanced glycation end products (RAGE)," in Proceedings of the 8th International Symposium on the Maillard reaction, no. SXI-7, p. 55, Charleston, SC, USA, 2004.

[66] A. M. Vincent, L. Perrone, K. A. Sullivan et al., "Receptor for advanced glycation end products activation injures primary sensory neurons via oxidative stress," Endocrinology, vol. 148, no. 2, pp. 548-558, 2007.

[67] A. M. Schmidt and D. M. Stern, "RAGE: a new target for the prevention and treatment of the vascular and inflammatory complications of diabetes," Trends in Endocrinology and Metabolism, vol. 11, no. 9, pp. 368-375, 2000.

[68] A. Goldin, J. A. Beckman, A. M. Schmidt, and M. A. Creager, "Advanced glycation end products: sparking the development of diabetic vascular injury," Circulation, vol. 114, no. 6, pp. 597-605, 2006.

[69] R. Bucala, K. J. Tracey, and A. Cerami, "Advanced glycosylation products quench nitric oxide and mediate defective endothelium-dependent vasodilatation in experimental diabetes," Journal of Clinical Investigation, vol. 87, no. 2, pp. 432-438, 1991.

[70] J. M. Forbes, L. T. L. Yee, V. Thallas et al., "Advanced glycation end product interventions reduce diabetes-accelerated atherosclerosis," Diabetes, vol. 53, no. 7, pp. 1813-1823, 2004.
[71] A. Soro-Paavonen, A. M. Watson, J. Li et al., "Receptor for advanced glycation end products (RAGE) deficiency attenuates the development of atherosclerosis in diabetes," Diabetes, vol. 57, no. 9, pp. 2461-2469, 2008.

[72] L. Park, K. G. Raman, K. J. Lee et al., "Suppression of accelerated diabetic atherosclerosis by the soluble receptor for advanced glycation end products," Nature Medicine, vol. 4, no. 9, pp. 1025-1031, 1998.

[73] T. Wendt, E. Harja, L. Bucciarelli et al., "RAGE modulates vascular inflammation and atherosclerosis in a murine model of type 2 diabetes," Atherosclerosis, vol. 185, no. 1, pp. 70-77, 2006.

[74] L. Sun, T. Ishida, T. Yasuda et al., "RAGE mediates oxidized LDL-induced pro-inflammatory effects and atherosclerosis in non-diabetic LDL receptor-deficient mice," Cardiovascular Research, vol. 82, no. 2, pp. 371-381, 2009.

[75] A. C. St-Pierre, B. Cantin, G. R. Dagenais et al., "Low-density lipoprotein subfractions and the long-term risk of ischemic heart disease in men: 13-year follow-up data from the Québec Cardiovascular Study," Arteriosclerosis, Thrombosis, and Vascular Biology, vol. 25, no. 3, pp. 553-559, 2005.

[76] F. J. Tames, M. I. Mackness, S. Arrol, I. Laing, and P. N. Durrington, "Non-enzymatic glycation of apolipoprotein B in the sera of diabetic and non-diabetic subjects," Atherosclerosis, vol. 93, no. 3, pp. 237-244, 1992.

[77] B. E. Brown, I. Rashid, D. M. van Reyk, and M. J. Davies, "Glycation of low-density lipoprotein results in the time-dependent accumulation of cholesteryl esters and apolipoprotein B-100 protein in primary human monocytederived macrophages," FEBS Journal, vol. 274, no. 6, pp. 1530-1541, 2007.

[78] H. Soran and P. N. Durrington, "Susceptibility of LDL and its subfractions to glycation," Current Opinion in Lipidology, vol. 22, no. 4, pp. 254-261, 2011.

[79] C. C. Hedrick, S. R. Thorpe, M. X. Fu et al., "Glycation impairs high-density lipoprotein function," Diabetologia, vol. 43, no. 3, pp. 312-320, 2000.

[80] C. Doucet, T. Huby, J. Ruiz, M. J. Chapman, and J. Thillet, "Non-enzymatic glycation of lipoprotein(a) in vitro and in vivo," Atherosclerosis, vol. 118, no. 1, pp. 135-143, 1995.

[81] J. Zhang, S. Ren, and G. X. Shen, "Glycation amplifies lipoprotein(a)-induced alterations in the generation of fibrinolytic regulators from human vascular endothelial cells," Atherosclerosis, vol. 150, no. 2, pp. 299-308, 2000.

[82] A. Stirban, M. Negrean, B. Stratmann et al., "Benfotiamine prevents macro- and microvascular endothelial dysfunction and oxidative stress following a meal rich in advanced glycation end products in individuals with type 2 diabetes," Diabetes Care, vol. 29, no. 9, pp. 2064-2071, 2006.

[83] S. B. Schwedler, P. Verbeke, H. Bakala et al., "N-phenacylthiazolium bromide decreases renal and increases urinary advanced glycation end products excretion without ameliorating diabetic nephropathy in C57BL/6 mice," Diabetes, Obesity and Metabolism, vol. 3, no. 4, pp. 230-239, 2001.

[84] D. Joshi, R. Gupta, A. Dubey et al., "TRC4186, a novel AGE-breaker, improves diabetic cardiomyopathy and nephropathy in Ob-ZSF1 model of type 2 diabetes," Journal of Cardiovascular Pharmacology, vol. 54, no. 1, pp. 72-81, 2009.

[85] B. H. Wolffenbuttel, C. M. Boulanger, F. R. Crijns et al., "Breakers of advanced glycation end products restore large artery properties in experimental diabetes," Proceedings of the National Academy of Sciences of the United States of America, vol. 95, no. 8, pp. 4630-4634, 1998. 
[86] G. Cheng, L. L. Wang, L. Long et al., "Beneficial effects of C36, a novel breaker of advanced glycation end products crosslinks, on the cardiovascular system of diabetic rats," British Journal of Pharmacology, vol. 152, no. 8, pp. 1196-1206, 2007.

[87] Y. Chen, E. M. Akirav, W. Chen et al., "RAGE ligation affects $\mathrm{T}$ cell activation and controls T cell differentiation," Journal of Immunology, vol. 181, no. 6, pp. 4272-4278, 2008.

[88] N. Marx, D. Walcher, N. Ivanova et al., "Thiazolidinediones reduce endothelial expression of receptors for advanced glycation end products," Diabetes, vol. 53, no. 10, pp. 2662-2668, 2004.

[89] S. Yamagishi and M. Takeuchi, "Nifedipine inhibits gene expression of receptor for advanced glycation end products (RAGE) in endothelial cells by suppressing reactive oxygen species generation," Drugs under Experimental and Clinical Research, vol. 30, no. 4, pp. 169-175, 2004.

[90] C. Cuccurullo, A. Iezzi, M. L. Fazia et al., "Suppression of RAGE as a basis of simvastatin-dependent plaque stabilization in type 2 diabetes," Arteriosclerosis, Thrombosis, and Vascular Biology, vol. 26, no. 12, pp. 2716-2723, 2006.

[91] F. Santilli, L. Bucciarelli, D. Noto et al., "Decreased plasma soluble RAGE in patients with hypercholesterolemia: effects of statins," Free Radical Biology and Medicine, vol. 43, no. 9, pp. 1255-1262, 2007.

[92] J. M. Forbes, S. R. Thorpe, V. Thallas-Bonke et al., "Modulation of soluble receptor for advanced glycation end products by angiotensin-converting enzyme-1 inhibition in diabetic nephropathy," Journal of the American Society of Nephrology, vol. 16, no. 8, pp. 2363-2372, 2005.

[93] J. Li, X. Qu, J. Yao et al., "Blockade of endothelialmesenchymal transition by a Smad3 inhibitor delays the early development of streptozotocin-induced diabetic nephropathy," Diabetes, vol. 59, no. 10, pp. 2612-2624, 2010. 


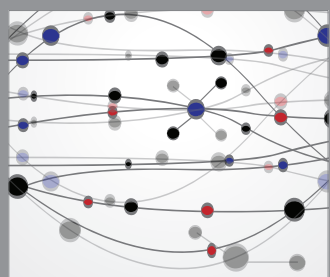

The Scientific World Journal
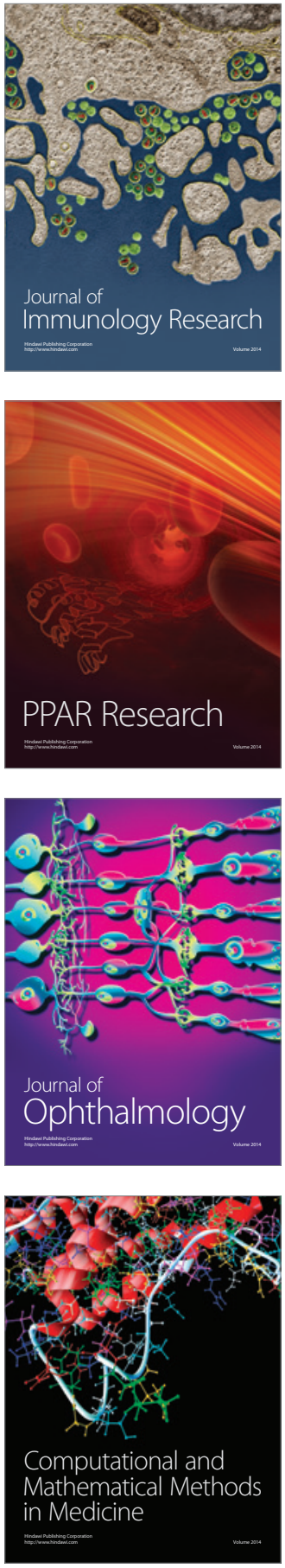

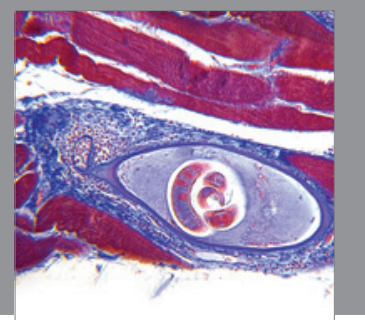

Gastroenterology

Research and Practice
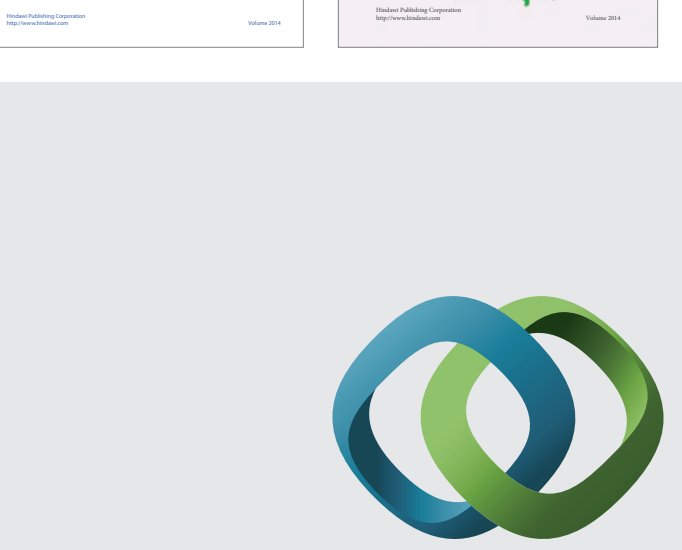

\section{Hindawi}

Submit your manuscripts at

http://www.hindawi.com
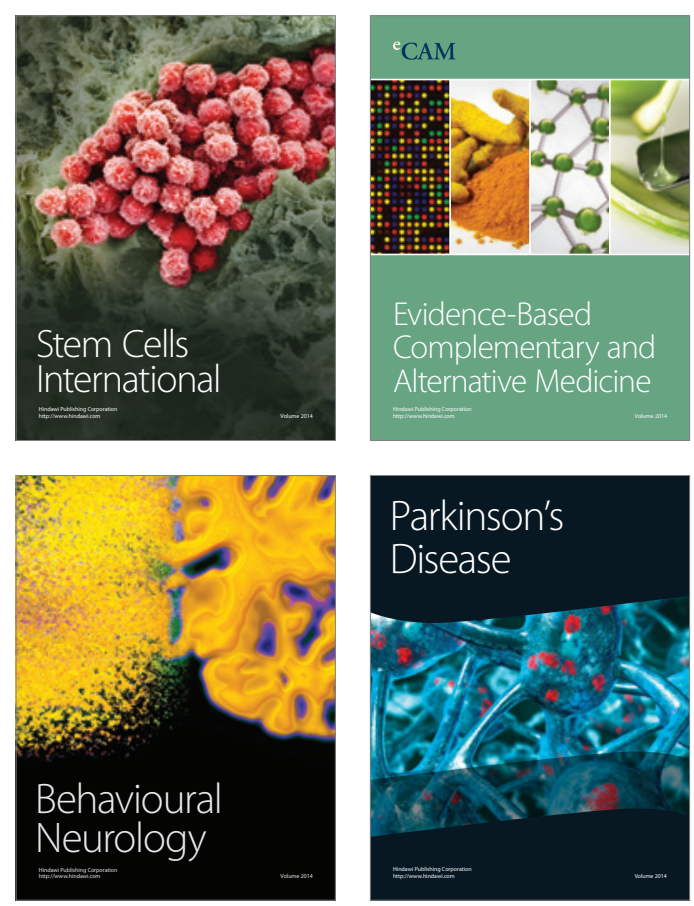

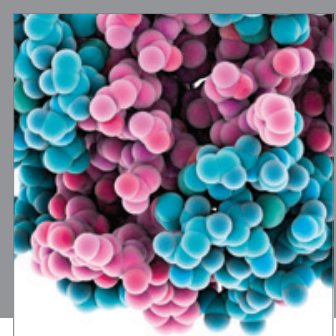

Journal of
Diabetes Research

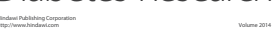

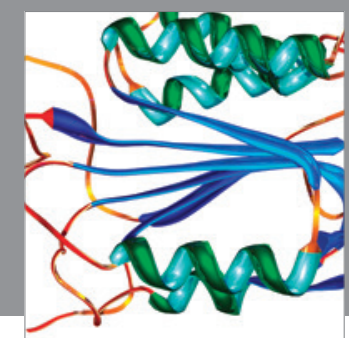

Disease Markers
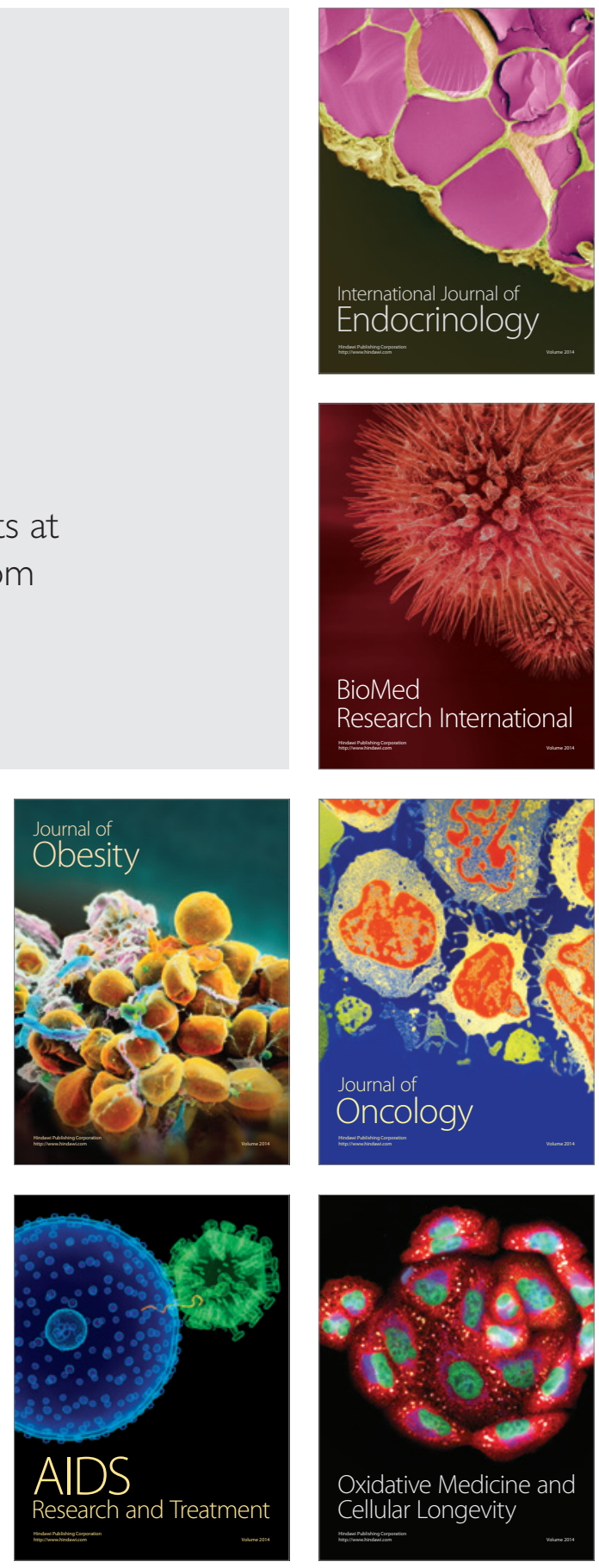